\title{
Near-occlusion is difficult to diagnose with common carotid ultrasound methods
}

\author{
Elias Johansson ${ }^{1,2}\left(\mathbb{D} \cdot\right.$ Davide Vanoli $^{3} \cdot$ Isa Bråten-Johansson ${ }^{1} \cdot$ Lucy Law $^{1} \cdot$ Richard I Aviv $^{4} \cdot$ Allan J Fox $^{4}$
}

Received: 12 October 2020 / Accepted: 3 March 2021 / Published online: 13 March 2021

(C) The Author(s) 2021, corrected publication 2021

\begin{abstract}
Purpose To assess the sensitivity and specificity of common carotid ultrasound method for carotid near-occlusion diagnosis. Methods Five hundred forty-eight patients examined with both ultrasound and CTA within 30 days of each other were analyzed. CTA graded by near-occlusion experts was used as reference standard. Low flow velocity, unusual findings, and commonly used flow velocity parameters were analyzed.

Results One hundred three near-occlusions, 272 conventional $\geq 50 \%$ stenosis, $162<50 \%$ stenosis, and 11 occlusions were included. Carotid ultrasound was 22\% (95\%CI 14-30\%; 23/103) sensitive and 99\% (95\%CI 99-100\%; 442/445) specific for near-occlusion diagnosis. Near-occlusions overlooked on ultrasound were found misdiagnosed as occlusions $(n=13,13 \%)$, conventional $\geq 50 \%$ stenosis $(n=65,63 \%)$ and $<50 \%$ stenosis $(n=2,2 \%)$. No velocity parameter or combination of parameters could identify the 65 near-occlusions mistaken for conventional $\geq 50 \%$ stenoses with $>75 \%$ sensitivity and specificity.

Conclusion Near-occlusion is difficult to diagnose with commonly used carotid ultrasound methods. Improved carotid ultrasound methods are needed if ultrasound is to retain its position as sole preoperative modality.
\end{abstract}

Keywords Carotid stenosis · Carotid near-occlusion $\cdot$ CT-angiography $\cdot$ Ultrasound

\section{Introduction}

Carotid near-occlusion is a variant of severe carotid stenosis where, in contrast to conventional $\geq 50 \%$ carotid stenosis, the stenosis causes the artery to reduce in size ("collapse") distal to the stenosis [1-3]. The collapse is considered a physiological response to reduction in pressure and flow. When the flow reduction is severe, the distal artery has a threadlike appearance

This manuscript was presented as oral presentation on the European Society for Neurosonology and Cerebral Hemodynamics, Linz, Austria 2019.

Elias Johansson

elias.johansson@umu.se

1 Department of Clinical Science, Umeå University, Umeå, Sweden

2 Wallenberg Center for Molecular Medicine (WCMM), Umeå University, Umeå, Sweden

3 Department of Public Health and Clinical Medicine, Umeå University, Umeå, Sweden

4 Department of Medical Imaging, Sunnybrook Health Science Center, University of Toronto, Toronto, Canada (near-occlusion with full collapse, Fig. 1a). With moderate flow reduction, the distal artery often is "normal-appearing" albeit small (near-occlusion without full collapse, Fig. 1b) [1-3]. In contrast to symptomatic conventional $\geq 50 \%$ stenosis, the recent guideline recommendations for symptomatic near-occlusion is for conservative non-surgical management $[4,5]$, based on the muted effect of carotid endarterectomy for these patients in the pooled NASCET and ECST post hoc analysis [1].

Despite a large number of studies of carotid stenosis, the approach to diagnose near-occlusion with ultrasound remains unclear [6-11]. World Federation of Neurology ultrasound guidelines do not include near-occlusion as a category [6]. El-Saden studied 20 near-occlusions and found that $30 \%$ could be identified by low stenosis flow velocity or collapsed distal appearance [8]. Based on this small study, North American carotid stenosis grading guidelines state that ICA PSV in near-occlusion is "high, low or undetectable," with only "low" being specific for near-occlusions (Fig. 2) [7]. Other studies have found that low flow velocity in the stenosis is very specific for near-occlusion $[9,10]$. However, none of these studies specified what "low" velocity was [8-10]. ElSaden provided no threshold for collapsed distal appearance [8]. Khangure et al. recently defined "low" velocity as ICA 
Fig. 1 Two cases of left-sided near-occlusion. a Near-occlusion with full collapse, sagittal CTA. Beyond a severe stenosis (white arrowhead), the distal ICA is significantly size-reduced with a threadlike appearance. Distal ICA is $0.8 \mathrm{~mm}$ in diameter. b Nearocclusion without full collapse, coronal CTA. Beyond severe stenosis (white arrowhead), the distal ICA is normal-appearing but relatively small (white arrow, $2.8 \mathrm{~mm}$ diameter), smaller than contralateral distal ICA (black arrowhead, $3.9 \mathrm{~mm}$ diameter) and similar to ECA (black arrow, $2.4 \mathrm{~mm}$ diameter)

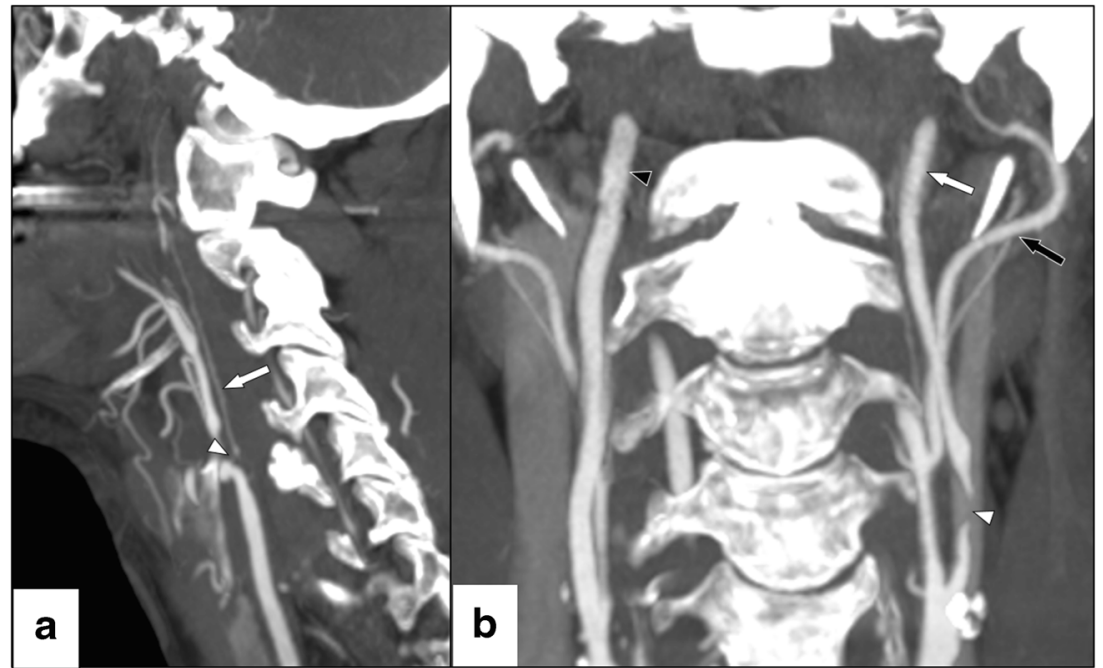

PSV $<125 \mathrm{~cm} / \mathrm{s}$ as this threshold is considered to separate $<50 \%$ stenosis from conventional $\geq 50 \%$ stenosis [11]. Khangure et al. found that only $7 / 46$ (15\%) of nearocclusions had this finding and that no commonly used velocity parameter was sensitive and specific for near-occlusion with high stenosis velocity [11]. However, Khangure et al. did not assess unusual findings that might indicate nearocclusion to the skilled observer (suspected near-occlusion) and was based on several databases [11]. None of these databases was dedicated to near-occlusion research [11].

The purpose of this study was to assess if commonly used ultrasound findings can be used to diagnose carotid nearocclusion.

\section{Materials and methods}

We evaluated a dedicated retrospective near-occlusion research cohort from a single center including all cases that underwent CTA and ultrasound within 30 days of each other between January 2010 and December 2014. Cases underwent either ultrasound, CTA, or both based on clinical decisions, increasingly using both as routine. All ultrasound examinations were performed within the Department of Clinical Physiology at the University Hospital of Northern Sweden. Ultrasound exams of poor quality (e.g., demonstrating extensive shadowing) were excluded. Cases with revascularization between exams were excluded. CTAs were performed at or sent to the Department of Radiology at the University Hospital of Northern Sweden. CTAs were performed as part of clinical routine using various machines and various protocols at the University Hospital of Northern Sweden and 11 referring hospitals.

\section{CTA image interpretation}

Near-occlusion was diagnosed when the distal extracranial ICA was reduced in size secondary to a proximal stenosis. Luminal reduction had to be visible as an extracranial ICA
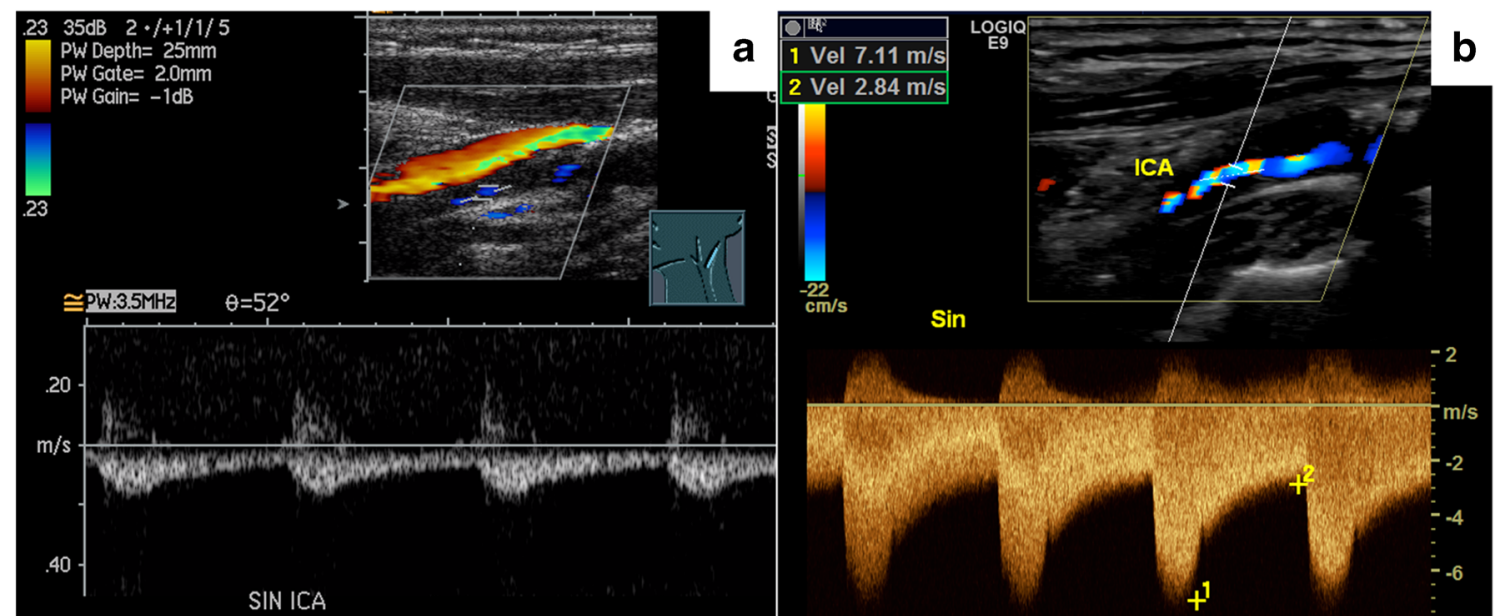

Fig. 2 Ultrasound findings in two cases with near-occlusion. a Severe stenosis with low stenosis velocity, distinguishable from conventional stenosis by the low velocity. b Severe stenosis with high stenosis velocity, difficult to distinguish from conventional stenosis 
asymmetry [12]. Diagnosis was established using a systematic interpretive approach, weighing the information of four features of near-occlusion (stenosis severity, distal ICA size, distal ICA asymmetry, and ICA/ECA ratio), mirroring the approach in NASCET for CTA $[1,2,12]$. ICA/ECA ratio was calculated by dividing distal ICA diameter with ipsilateral ECA diameter just proximal to its terminal bifurcation, usually situated behind the jaw [12]. In cases of contralateral occlusion, ipsilateral near-occlusion diagnosis was considered when distal ICA was clearly size-reduced compared to ECA. Bilateral near-occlusion required bilateral clear size reduction compared to ECA. A conservative approach was used, only diagnosing near-occlusion when it was the most reasonable diagnosis. Asymmetric distal ICAs associated with asymmetric Circle of Willis were considered an important mimic to near-occlusion, as this is seen in $8 \%$ of persons without steno-occlusive disease [13]. Among the near-occlusions, full collapse was defined as a threadlike distal lumen, often smaller than the ECA (except when ECA was also reduced), whereas those without full collapse had a normal-appearing albeit small distal ICA [1-3]. Eight near-occlusions with full collapse with contrast visible distal to the stenosis but not yet reaching the skull base at the time of image capture were arbitrarily assigned a distal ICA diameter of $0.5 \mathrm{~mm}$ in the analyses. Occlusion was diagnosed when no contrast was visible beyond the lesion, accompanied by a rounded stump. In cases with a tiny residual lumen, where contrast opacity was reduced by technical limitations (e.g., partial volume effect), the luminal diameter was arbitrarily recorded as $0.5 \mathrm{~mm}$ for analyses. Among cases with conventional stenosis, the degree of stenosis was measured using established NASCET criteria [14].

The 4403 CTA exams (4042 patients) performed during the study period were re-evaluated by one observer (EJ, 5 years of carotid grading experience) [13]. Twenty-five cases had multiple eligible CTAs ( $<30$ days to ultrasound without revascularization in between and acceptable exam quality). In 24 , the exam closest to ultrasound was used. In one case, an earlier CTA was used even though a second CTA was closer to the ultrasound, because the second CTA revealed progression to symptomatic occlusion. All cases of suspected nearocclusion or near-occlusion mimics were re-evaluated in a blinded fashion by a second observer (AF, $>40$ years of carotid grading experience). Inter-rater disagreements were settled by a consensus discussion. Of the exams assessed by both observers, a random subset of 49 exams was assessed twice, for intra-rater reliability. All CTA reviews were performed blinded to ultrasound findings.

\section{Carotid ultrasound}

Several experienced sonographers who were blinded to the CTA results performed the carotid ultrasound examinations as part of clinical routine. Specialists in clinical physiology (six in total) reviewed the images live and took additional images when needed. The same specialist signed the report. iU22 (Philips, Amsterdam, Netherlands), LogiqE9 (GE, Boston, USA), and S2000 and Acuson Sequoia (both Siemens, Munich, Germany) systems were used. A standard protocol was used, including visualization of the common carotid artery (CCA), ICA, and ECA in transverse and sagittal section, with and without color doppler. Pulsed doppler velocity image was routinely gathered in mid CCA and at the point of maximum stenosis, but not distal to the stenosis. Stenosis velocity was the main feature used for stenosis grading, not diameter measurement of the stenosis. Cases with no measurable flow were categorized as occlusion. Cases without detectable flow through the stenosis but with flow signal detectable beyond the stenosis with an ICA flow profile were categorized as likely near-occlusion (i.e., not likely occluded, as flow through the stenosis is assumed). For flow velocity analyses, likely near-occlusions were arbitrarily assigned stenosis PSV $10 \mathrm{~cm} / \mathrm{s}$ and EDV $3 \mathrm{~cm} / \mathrm{s}$ as there was an assumed flow, not zero flow. Two observers (IBJ and LL) retrospectively extracted PSV and end-diastolic velocity (EDV) data from stored images between them (no double extraction) for velocity analyses. Reported diagnosis, including cases with low PSV, was diagnosed as near-occlusion or $<50 \%$ stenosis, and any mention of unusual findings that might suggest near-occlusion despite high stenosis PSV (suspected nearocclusion; i.e., possibly not a conventional stenosis) was noted by one observer (EJ). Suspected near-occlusion were cases where near-occlusion was at least suggested in the report despite high PSV, regardless of rationale. All ultrasound data extraction was blinded to CTA findings.

Since a threshold for "low PSV" is not well defined in the literature, we used both a Low PSV and intermediate PSV group in order to present as much data as possible. As low $P S V$ should be specific for near-occlusion, to define it as lower than what constitutes $\mathrm{a} \geq 50 \%$ stenosis is reasonable. To reproduce the methods of Khangure et al., "Low PSV' was defined as $<125 \mathrm{~cm} / \mathrm{s}$, in turn based on that $\geq 125 \mathrm{~cm} / \mathrm{s}$ is the threshold for $\geq 50 \%$ stenosis in two international consensus criteria [7, 15]. " $H i g h ~ P S V$ " was defined as $\geq 145 \mathrm{~cm} / \mathrm{s}$ as this was the locally used threshold defined for $\geq 50 \%$ stenosis based on published criteria [16]. The subsequent range in between, $125-144 \mathrm{~cm} / \mathrm{s}$, considered $\geq 50 \%$ by some, not others, was categorized as "Intermediate PSV." The reported diagnosis was used to distinguish between $<50 \%$ stenosis and nearocclusions among cases with low and intermediate PSV. To combine all approaches, "Any indication of near-occlusion" was defined as the combination of suspected near-occlusion, intermediate PSV, low PSV, and likely near-occlusion. Cases diagnosed as $<50 \%$ stenosis in the ultrasound report was not considered to have any indication of near-occlusion.

Pulsatility index (PI) was calculated as (PSV-EDV)/mean velocity, where mean velocity was calculated as $\mathrm{EDV}+(\mathrm{PSV}-$ 
EDV) $/ 3$ [11]. PSV and EDV ratios were calculated by dividing stenosis with CCA findings.

\section{Analysis and statistics}

The side with the most relevant finding was analyzed. Any indication of near-occlusion on ultrasound was the main ultrasound outcome. Analyses of flow velocities were performed mainly to assess if flow velocity could be diagnostically useful among cases with high PSV without any indication of near-occlusion, but also to present flow velocities in all near-occlusions. Cases diagnosed as occlusion on ultrasound were excluded from flow velocity analyses.

We used mean, standard deviation (SD), 95\% confidence intervals $(95 \% \mathrm{CI}), 2$-sided $\chi^{2}$-test, $t$-test, and ANOVA using REGW-Q post hoc test, as specified. Receiver operating characteristic was used, analyzing area under the curve (AUC); diagnostic thresholds were set for maximal Youden index (where sum of sensitivity and specificity is maximum) and for maximal Hirsch-index (H-index, where sensitivity and specificity are as high and similar as possible), calculating resulting sensitivity, specificity, and positive and negative predictive values. We assessed all 28 possible combinations of two velocity parameters: For each combination, we first assessed a scatterplot to determine the reasonable range of thresholds, if values above or below the thresholds should indicate near-occlusion, and if "and" or "and/or" type of combination should be used. Then, all possible combinations of thresholds within the reasonable ranges were assessed to determine which combination produced the highest Youden index and H-index. $p<0.05$ was pre-specified as border for statistical significance. SPSS 24.0 and Microsoft Excel were used in the calculations.

\section{Results}

Five hundred forty-eight patients were included (Fig. 3). Mean age was higher in patients with conventional $\geq 50 \%$ stenosis than other stenosis groups, and occlusions tended to be less often symptomatic and tended to have longer delay between exams than other stenosis groups (Table 1). Large differences in CTA measurements were noted (Table 1). Of the 272 cases with conventional $\geq 50 \%$ stenosis, $30(11 \%)$ had smaller ipsilateral distal ICA compared to contralateral ICA attributed to Circle of Willis variation (18 ipsilateral A1-hypo/ aplasia, 4 contralateral large or fetal Pcom, 8 both).

Twenty-two percent $(95 \%$ CI $14-30 \% ; 23 / 103)$ of nearocclusions had any indication of near-occlusion, more often among those with full collapse $(41 \%$; $95 \%$ CI $25-57 \%$; 16/39) than those without full collapse (11\%; 95\% CI 3-19\%; 7/64; $p$ $<0.001, \chi^{2}$ ) (Fig. 4). In those with full collapse, low PSV and likely near-occlusion both contributed to a large share of
4810 patients with $\mathrm{CTA}^{*}$ and/or DUS

769 DUS alone: +

$510<50 \%$ stenosis

137 symptomatic $\geq 50 \%$ stenosis

114 asymptomatic $\geq 50 \%$ stenosis

8 occlusions

3398 CTA alone:

$3159<50 \%$ stenosis

73 symptomatic $\geq 50 \%$ stenosis

124 asymptomatic $\geq 50 \%$ stenosis

42 occlusions

643 patients with CTA and DUS

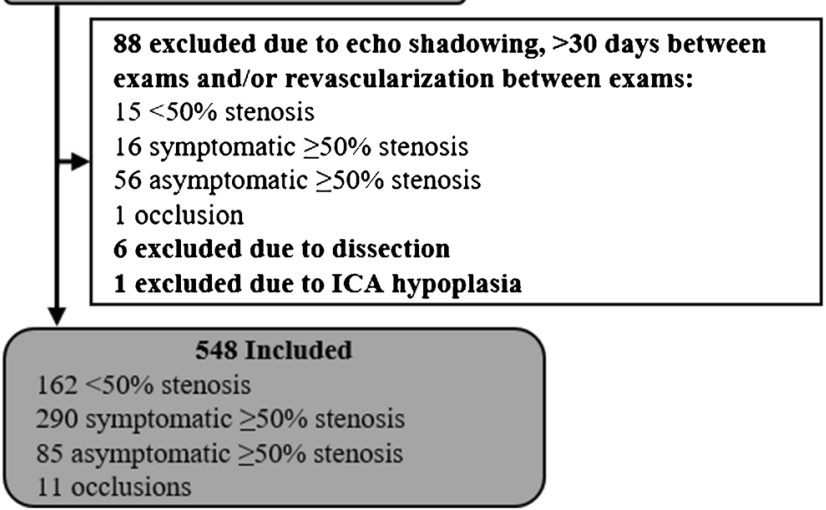

Fig. 3 Study flow chart. *Excluding 37 exams with insufficient quality and one that could not be retrieved. ${ }^{\dagger}$ Only cases without CTA (from any referral source) where DUS referral was from the stroke unit or case sent to stroke unit after identification of stenosis or occlusion on DUS

detected near-occlusion (both $n=6$ ) (Table 2). In those without full collapse, all subsets of the combined outcome were similarly common (Table 2). Two near-occlusions (with and without full collapse each) had intermediate PSV (but none with low PSV) and were mistaken for $<50 \%$ stenosis in the ultrasound report. Near-occlusions with full collapse were more often mistaken for occlusion than near-occlusions without full collapse $(23 \%$; $95 \%$ CI $9-37 \%$ and $6 \%$; $95 \%$ CI 0 $12 \%$; respectively; $p=0.02, \chi^{2}$ ). There were 3 false positive near-occlusions on ultrasound, 1 erroneously suspected nearocclusion that was a 54\% stenosis on CTA and 2 likely nearocclusion that were occlusions on CTA. No case with conventional stenosis and low or intermediate PSV was mistaken for near-occlusion. Thus, any indication of near-occlusion was $>99 \%$ specific (95\% CI 99-100\%; 442/445). When only cases with $\leq 7$ days between ultrasound and CTA were considered, the sensitivity $(20 \%$; $95 \%$ CI $11-28 \%$; 17/86) and specificity $(99 \%, 95 \%$ CI $98-100 \% ; 371 / 374)$ of ultrasound was similar to the outcome of the entire cohort.

On group level, near-occlusions had higher mean stenosis PSV, stenosis EDV, PSV ratio and EDV ratio, and lower CCA PSV and CCA EDV than conventional $\geq 50 \%$ stenosis (Table 3). When only assessing the 65 near-occlusions with high stenosis PSV and without any indication of nearocclusion on ultrasound, these differences were similar or 
Table 1 Baseline characteristics and CTA findings

\begin{tabular}{|c|c|c|c|c|c|}
\hline Characteristic & $\begin{array}{l}<50 \% \\
\text { stenosis } \\
(n=162)\end{array}$ & $\begin{array}{l}\text { Conventional } \geq 50 \% \\
\text { stenosis } \\
(n=272)\end{array}$ & $\begin{array}{l}\text { Near- } \\
\text { occlusion } \\
(n=103)\end{array}$ & $\begin{array}{l}\text { Occlusion } \\
(n=11)\end{array}$ & $p$ \\
\hline Age years mean $(\mathrm{SD})$ & $68(9)$ & $72(7)$ & $69(9)$ & $65(11)$ & $<0.001^{\mathrm{a}, \mathrm{b}}$ \\
\hline Women n (\%) & $58(36)$ & $83(31)$ & $29(28)$ & $2(18)$ & $0.41^{\mathrm{c}}$ \\
\hline Days between exams mean (SD) & $5(7)$ & $5(6)$ & $4(6)$ & $10(11)$ & $0.07^{\mathrm{a}}$ \\
\hline $\begin{array}{l}\text { Symptomatic presentation }{ }^{\mathrm{d}} n \\
(\%)\end{array}$ & $\mathrm{N} / \mathrm{A}$ & $211(78)^{d}$ & $79(77)^{d}$ & $4(36)$ & $0.09^{\mathrm{c}, \mathrm{e}}$ \\
\hline $\begin{array}{l}\text { CTA: Stenosis diameter mm } \\
\text { mean }(\mathrm{SD})\end{array}$ & N/A & $1.3(0.4)$ & $0.7(0.2)$ & N/A & $<0.001^{\mathrm{f}}$ \\
\hline $\begin{array}{l}\text { CTA: Distal ICA diameter mm } \\
\text { mean (SD) }\end{array}$ & $\mathrm{N} / \mathrm{A}$ & $4.2(0.6)$ & $2.3(0.9)$ & N/A & $<0.001^{\mathrm{f}}$ \\
\hline CTA: ICA ratio mean (SD) & $\mathrm{N} / \mathrm{A}$ & $0.97(0.12)$ & $\begin{array}{l}0.52 \\
(0.24)\end{array}$ & $\mathrm{N} / \mathrm{A}$ & $<0.001^{\mathrm{f}}$ \\
\hline $\begin{array}{l}\text { CTA: ICA/ECA-ratio mean } \\
\text { (SD) }\end{array}$ & N/A & $1.64(0.43)$ & $\begin{array}{l}0.81 \\
(0.36)\end{array}$ & N/A & $<0.001^{\mathrm{f}}$ \\
\hline $\begin{array}{l}\text { CTA: Near-occlusion with full } \\
\text { collapse } n(\%)\end{array}$ & N/A & N/A & $39(38)$ & $\mathrm{N} / \mathrm{A}$ & N/A \\
\hline
\end{tabular}

ICA ratio: ipsilateral/contralateral distal ICA diameter. ICA/ECA ratio: distal ipsilateral ICA/ipsilateral ECA. Stenosis diameter: smallest luminal diameter in the stenosis. N/A: not applicable.

${ }^{\mathrm{a}}$ ANOVA

${ }^{\mathrm{b}}$ On post hoc test, conventional $\geq 50 \%$ stenosis had higher mean age than all other groups at $p=0.02$; with no difference between the other three groups $(p=0.54)$

${ }^{\mathrm{c}} 2$-sided $\chi^{2}$-test

${ }^{\mathrm{d}}$ Symptomatic presentation: The stenosis/occlusion was ipsilateral to a recent ischemic cerebrovascular event, $<50 \%$ stenoses are not considered symptomatic. Of the 92 cases with asymptomatic stenosis/occlusion, most (78\%) were detected due to a suspected or confirmed cerebrovascular event (but did not have a recent ipsilateral ischemic event), $6 \%$ were incidental when examined for other diseases, $6 \%$ were follow-up exams of known asymptomatic stenosis, $5 \%$ were due to bruits, $4 \%$ were due to very late management of cerebrovascular event $(>6$ months after the event), $1 \%$ was found in research projects

${ }^{\mathrm{e}}$ When comparing only conventional $\geq 50 \%$ stenosis and near-occlusion, no difference was seen $(p=0.89)$

${ }^{\mathrm{f}} T$-test

more pronounced (Table 3). No single ultrasound parameter had reasonable sensitivity and specificity to discriminate these 65 near-occlusions from conventional $\geq 50 \%$ stenosis. EDV ratio had the highest AUC (0.79) and Youden index, whereas stenosis EDV had the highest H-index (Table 4). Of the 28 possible combinations of parameters with adjusted thresholds, three combinations had both the highest H-index and Youden index, and were foremost based on EDV (Table 4). No parameter or combination of parameters was $>75 \%$ sensitive and specific for near-occlusion.

Blinded inter-rater reliability for near-occlusion diagnosis on CTA was good: kappa 0.80 (95\%CI 0.75-0.84). Intra-rater reliability was kappa $0.75(95 \% \mathrm{CI} 0.60-0.90)$ and 0.88 (95\% CI 0.76-0.99) for each reviewer.

\section{Discussion}

The main finding of this study was that most (63\%) nearocclusions have high stenosis velocities without any clear difference from conventional stenosis in other commonly used parameters. Almost all commonly used velocity parameters were significantly higher or lower in this high-velocity nearocclusion compared with conventional $\geq 50 \%$ stenosis on group level. However, considerable overlap resulted in that no commonly used velocity parameters had $>75 \%$ sensitivity and specificity, alone or in combination.

Near-occlusion is an angiographic diagnosis defined by artery size reduction beyond a severe stenosis [1-3]. Extent of distal ICA size reduction required for near-occlusion diagnosis has varied between reports. In studies where low stenosis velocity was relatively sensitive $(71 \%)$ and very specific (99\%) for near-occlusion, near-occlusion was defined as full collapse ("string sign") alone [2, 9, 10]. We included both severe distal ICA collapses (with full collapse, sometimes called "string sign") and subtle distal ICA collapses (without full collapse), similar to the pooled analysis for near-occlusion of NASCET and ECST [1]. Many clinicians do not pay attention to that $94 \%$ of near-occlusion in the pooled analysis of NASCET and ECST were near-occlusions without full collapse [1-3]. As this pooled analysis is the foundation of guideline recommendations $[4,5]$, the guideline recommendations 
Fig. 4 Comparison of CTangiography (bars) and ultrasound findings (colors). Nearocclusion on ultrasound denotes any indication of near-occlusion, where two cases with $<50 \%$ stenosis had intermediate PSV and diagnosed as $<50 \%$ stenosis in the report

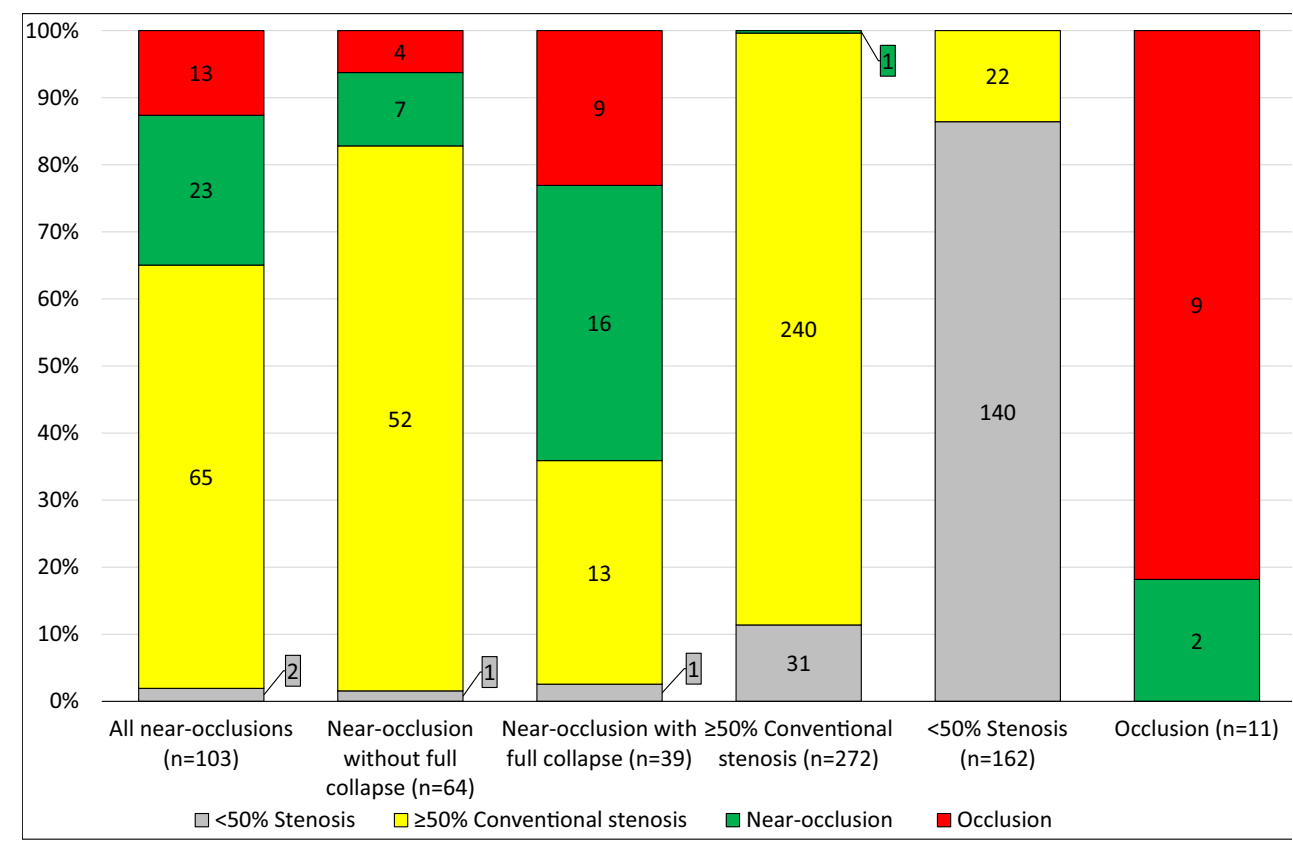

are most applicable to near-occlusion without full collapse. Therefore, in studies of near-occlusion, those without full collapse should be included in the near-occlusion definition. However, this results in a reduced sensitivity of nearocclusion with carotid ultrasound.

With the expanded definition of near-occlusion, the sensitivity of commonly used ultrasound parameters for nearocclusion was low, but specificity was high, both in the current study and in Khangure et al., that also used this expanded definition [11]. Similarly, Palacios-Mendoza et al. recently confirmed that many near-occlusions are mistaken for conventional stenosis, but provided no velocity data or detailed definition [17]. We found a slightly higher sensitivity for the combined any indication of near-occlusion approach (22\%) than Khangure et al. (15\%) [11]. Khangure et al. only considered low stenosis PSV $(<125 \mathrm{~cm} / \mathrm{s})$ and was unclear about how likely near-occlusions were analyzed [11]; the difference in sensitivity was accounted for by our findings in the suspected near-occlusion and intermediate PSV subset of any indication of near-occlusion. However, similar to Khangure et al., we found that no velocity parameter in the stenosis or CCA (i.e., those commonly used), alone or in combination, could differentiate between conventional $\geq 50 \%$ stenosis and the remaining near-occlusions with both sufficient sensitivity and specificity [11]. As many Youden index-based thresholds provide large differences between sensitivity and specificity,
Table 2 Types of near-occlusion findings on carotid ultrasound

\begin{tabular}{lllll}
\hline Ultrasound finding & $\begin{array}{l}\text { Near-occlusion } \\
\text { without full collapse }\end{array}$ & $\begin{array}{l}\text { Near-occlusions with } \\
\text { full collapse }\end{array}$ & $\begin{array}{l}\geq 50 \% \\
\text { conventional } \\
\text { stenosis }\end{array}$ & Occlusion \\
\hline $\begin{array}{l}\text { High PSV with suspected } \\
\text { near-occlusion }\end{array}$ & $3^{\mathrm{a}}$ & $3^{\mathrm{b}}$ & $1^{\mathrm{c}}$ & 0 \\
$\begin{array}{l}\text { Intermediate PSV } \\
\text { Low PSV }\end{array}$ & 1 & 1 & 0 & 0 \\
Likely near-occlusion & 1 & 6 & 0 & 0 \\
\hline
\end{tabular}

All values are $n$. High PSV: stenosis PSV $\geq 145 \mathrm{~cm} / \mathrm{s}$. Intermediate PSV: stenosis PSV $125-144 \mathrm{~cm} / \mathrm{s}$. Low PSV: stenosis PSV $<125 \mathrm{~cm} / \mathrm{s}$. Likely near-occlusion: no flow detectable in the stenosis but noted in a low-flow artery with ICA profile beyond the stenosis

${ }^{\text {a }}$ Two by low distal velocity, one by mismatch between a tiny stenosis lumen on B-mode, but indication of moderate degree stenosis by stenosis PSV $(307 \mathrm{~cm} / \mathrm{s})$

${ }^{\mathrm{b}}$ Two by mismatch between tiny stenosis lumen on B-mode, but indication of moderate degree stenosis by stenosis PSV (180 cm/s and $254 \mathrm{~cm} / \mathrm{s}$ ), one by very high stenosis PI (PSV $494 \mathrm{~cm} / \mathrm{s}$, EDV $16 \mathrm{~cm} / \mathrm{s}$, PI 2.73 )

${ }^{\mathrm{c}}$ Mismatch between a tiny stenosis lumen on B-mode, but indication of moderate degree stenosis by stenosis PSV $(203 \mathrm{~cm} / \mathrm{s})$, CTA showed $54 \%$ stenosis 
Table 3 Group level differences in ultrasound parameters between conventional $\geq 50 \%$ stenosis, all near-occlusions and nearocclusions without any indication of near-occlusion on ultrasound (those currently missed). The 13 near-occlusion cases with occlusion finding on ultrasound excluded

\begin{tabular}{|c|c|c|c|c|c|c|}
\hline $\begin{array}{l}\text { Ultrasound } \\
\text { parameter }\end{array}$ & $\begin{array}{l}\text { Missing } \\
\text { data }\end{array}$ & $\begin{array}{l}\text { Conventional } \\
\geq 50 \% \\
\text { stenosis } \\
(n=272)\end{array}$ & $\begin{array}{l}\text { All near- } \\
\text { occlusions } \\
(n=90)\end{array}$ & $\begin{array}{l}\text { Near-occlusion without any } \\
\text { indication of near-occlusion } \\
\text { on ultrasound } \\
(n=65)\end{array}$ & $\begin{array}{l}p^{\mathrm{a}} \\
(t \text {-test })\end{array}$ & $\begin{array}{l}p^{\mathrm{b}} \\
(t \text {-test })\end{array}$ \\
\hline $\begin{array}{c}\text { Stenosis } \\
\text { PSV }\end{array}$ & 0 & 289 (138) & 343 (197) & $430(141)$ & 0.02 & $<0.001$ \\
\hline $\begin{array}{c}\text { Stenosis } \\
\text { EDV }\end{array}$ & 1 & $94(68)$ & 117 (94) & $150(87)$ & 0.04 & $<0.001$ \\
\hline CCA PSV & 10 & $73(25)$ & $65(20)$ & $65(19)$ & 0.003 & 0.01 \\
\hline CCA EDV & 10 & $15(6)$ & $10(5)$ & $10(4)$ & $<0.001$ & $<0.001$ \\
\hline Stenosis PI & 1 & $1.32(0.35)$ & $\begin{array}{l}1.33 \\
(0.47)\end{array}$ & $1.26(0.43)$ & 0.80 & 0.27 \\
\hline CCA PI & 10 & $1.73(0.30)$ & $\begin{array}{l}1.95 \\
(0.31)\end{array}$ & $1.91(0.28)$ & $<0.001$ & $<0.001$ \\
\hline PSV ratio & 10 & $4.4(2.8)$ & $6.1(4.5)$ & $7.5(4.3)$ & 0.001 & $<0.001$ \\
\hline $\mathrm{EDV}^{\text {ratio }^{\mathrm{c}}}$ & 11 & $7.7(7.4)$ & $\begin{array}{l}13.7 \\
\quad(12.2)\end{array}$ & $16.4(10.8)$ & $<0.001$ & $<0.001$ \\
\hline
\end{tabular}

All values are mean (SD). Stenosis PSV, Stenosis EDV, CCA PSV, and CCA EDV are in $\mathrm{cm} / \mathrm{s}$. PI = pulse difference/mean velocity, i.e., $($ PSV-EDV) / $(E D V+((P S V-E D V) / 3) . P S V$ ratio = stenosis PSV / CCA PSV. EDV ratio $=$ stenosis $\mathrm{EDV} / \mathrm{CCA} \mathrm{EDV}$

${ }^{\text {a }}$ Conventional $\geq 50 \%$ stenosis compared with all near-occlusions

${ }^{\mathrm{b}}$ Conventional $\geq 50 \%$ stenosis compared with near-occlusion without any indication of near-occlusion on ultrasound

${ }^{\mathrm{c}}$ One case with $0 \mathrm{~cm} / \mathrm{s}$ CCA EDV was arbitrarily set to EDV ratio 20 we added the H-index to clarify that the modest performance of ultrasound was not a result of poor choice of thresholds.

It remains unclear how to best detect near-occlusion on carotid ultrasound, although it is certain that improvements are needed. First, it is unclear what the best threshold for a "low stenosis velocity" should be. A relevant factor is that cases below this velocity threshold will be diagnosed as either near-occlusions or $<50 \%$ stenosis based on visual inspection of the stenosis severity. We found that three cases were misclassified on such visual inspection in routine practice, two near-occlusions as $<50 \%$ stenosis and one $54 \%$ stenosis as near-occlusion, highlighting that this approach is not without problems. Similar misdiagnosis by interpreting nearocclusion with low flow findings as $<50 \%$ stenosis has been reported [11]. With these three misdiagnoses having stenosis PSV 133-203 cm/s, the best stenosis PSV threshold for "low velocity" is likely slightly above $125 \mathrm{~cm} / \mathrm{s}$, but dedicated prospective studies are needed to clarify this issue. Furthermore, suspected near-occlusions were not pre-specified categories, hence not systematically used in our entire cohort, some with similar findings might have been missed. All these findings have been reported previously $[6,9,18]$, and additional types of unusual findings might be possible. Distal artery size was not systematically assessed, in large part due to the lack of diagnostic threshold for such a measurement [7, 8]. However, in our experience from angiography, the reduced artery size of many near-occlusions is modest (not clear unless comparing with other arteries) and only visible well beyond the bulb, a region commonly not reachable with ultrasound. Therefore, it is reasonable to suspect that assessment of distal artery size on ultrasound might not be very sensitive for near-occlusion. After this cohort was examined, low velocity distal to the stenosis has emerged as a possible new method specific for near-occlusion [18], i.e., not indicative for severe conventional stenosis as indicated in a guideline [6]. Also, ultrasound contrast might improve separation of occlusion and nearocclusion [19]. Thus, with improved definition of low flow, vigilance for unusual findings, and novel methods, better diagnostic outcomes for near-occlusion can likely be achieved. Therefore, our results are not indicative of best possible carotid ultrasound outcomes, but rather indicative of what many routine ultrasound laboratories are likely to currently achieve.

Ultrasound as the sole preoperative modality is accepted or recommended in guidelines [4, 5], which is supported by the findings of a systematic assessment and review [20, 21]. However, these assessments focused on discrimination of $50 \%$ and $70 \%$ stenosis and omitted near-occlusion, as did all their underlying ultrasound studies $[20,21]$. Hence, when the community decided that ultrasound was reasonable as sole preoperative modality, the low sensitivity for near-occlusion with commonly used carotid ultrasound methods was not considered. As the difference between near-occlusion and conventional stenosis is management-altering according to current guidelines [4, 5], improvements in carotid ultrasound methods are needed if carotid ultrasound is to retain this prominent role. Also, the role of ultrasound might change in the 
Table 4 Diagnostic analysis of discriminative ability of ultrasound parameters to separate conventional $\geq 50 \%$ stenosis and near-occlusions without any indication of near-occlusion on ultrasound (the subset currently missed). Cases with occlusion finding on ultrasound excluded. All single parameters and the three best combinations of parameters (out of 28) presented

Single parameters

\begin{tabular}{|c|c|c|c|c|c|c|}
\hline Parameter & AUC $(95 \% \mathrm{CI})$ & Threshold & Sensitivity & Specificity & PPV & NPV \\
\hline Stenosis PSV & $\begin{array}{l}0.76 \\
(0.71-0.82)\end{array}$ & $\begin{array}{l}\geq 305^{\mathrm{a}} \\
\geq 361^{\mathrm{b}}\end{array}$ & $\begin{array}{l}86(78-95 ; 56 / 65) \\
71(59-82 ; 46 / 65)\end{array}$ & $\begin{array}{l}61(55-67 ; 166 / 272) \\
71(66-76 ; 193 / 272)\end{array}$ & $\begin{array}{l}35(27-42 ; 56 / 162) \\
37(28-45 ; 46 / 125)\end{array}$ & $\begin{array}{l}95(92-98 ; 166 / 175) \\
91(87-95 ; 193 / 212)\end{array}$ \\
\hline Stenosis EDV & $\begin{array}{l}0.71 \\
(0.64-0.79)\end{array}$ & $\begin{array}{l}\geq 114^{\mathrm{a}} \\
\geq 110^{\mathrm{b}}\end{array}$ & $\begin{array}{l}72(61-83 ; 47 / 65) \\
72(61-83 ; 47 / 65)\end{array}$ & $\begin{array}{l}75(70-80 ; 204 / 271) \\
74(69-79 ; 201 / 271)\end{array}$ & $\begin{array}{l}41(32-50 ; 47 / 114) \\
40(31-49 ; 47 / 117)\end{array}$ & $\begin{array}{l}92(88-96 ; 204 / 222) \\
92(88-95 ; 201 / 219)\end{array}$ \\
\hline CCA PSV & $\begin{array}{l}0.57 \\
(0.50-0.65)\end{array}$ & $\begin{array}{l}\leq 93^{\mathrm{a}} \\
\leq 68^{\mathrm{b}}\end{array}$ & $\begin{array}{l}98(95-100 ; 64 / 65) \\
54(41-66 ; 35 / 65)\end{array}$ & $\begin{array}{l}19(14-23 ; 49 / 262) \\
55(46-61 ; 144 / 262)\end{array}$ & $\begin{array}{l}23(18-28 ; 64 / 277) \\
23(16-30 ; 35 / 153)\end{array}$ & $\begin{array}{l}98(94-100 ; 49 / 50) \\
83(77-82 ; 144 / 174)\end{array}$ \\
\hline CCA EDV & $\begin{array}{l}0.70 \\
(0.63-0.77)\end{array}$ & $\begin{array}{l}\leq 9^{\mathrm{a}} \\
\leq 12^{\mathrm{b}}\end{array}$ & $\begin{array}{l}45(35-57 ; 29 / 65) \\
68(56-79 ; 44 / 65)\end{array}$ & $\begin{array}{l}84(79-88 ; 219 / 262) \\
60(54-66 ; 156 / 262)\end{array}$ & $\begin{array}{l}40(29-52 ; 29 / 72) \\
29(22-37 ; 44 / 150)\end{array}$ & $\begin{array}{l}86(82-90 ; 219 / 255) \\
88(83-93 ; 156 / 177)\end{array}$ \\
\hline Stenosis PI & $\begin{array}{l}0.57 \\
(0.48-0.65)\end{array}$ & $\begin{array}{l}\leq 1.09^{\mathrm{a}} \\
\leq 1.26^{\mathrm{b}}\end{array}$ & $\begin{array}{l}42(53-76 ; 27 / 65) \\
57(45-69 ; 37 / 65)\end{array}$ & $\begin{array}{l}74(69-79 ; 200 / 271) \\
54(48-60 ; 146 / 271)\end{array}$ & $\begin{array}{l}28(19-37 ; 27 / 98) \\
23(16-29 ; 37 / 162)\end{array}$ & $\begin{array}{l}84(79-89 ; 200 / 238) \\
84(78-89 ; 146 / 174)\end{array}$ \\
\hline CCA PI & $\begin{array}{l}0.67 \\
(0.60-0.75)\end{array}$ & $\begin{array}{l}\geq 1.87^{\mathrm{a}} \\
\geq 1.87^{\mathrm{b}}\end{array}$ & $\begin{array}{l}65(53-76 ; 42 / 65) \\
65(53-76 ; 42 / 65)\end{array}$ & $\begin{array}{l}65(59-71 ; 171 / 262) \\
65(59-71 ; 171 / 262)\end{array}$ & $\begin{array}{l}32(24-40 ; 42 / 133) \\
32(24-40 ; 42 / 133)\end{array}$ & $\begin{array}{l}88(84-93 ; 171 / 194) \\
88(84-93 ; 171 / 194)\end{array}$ \\
\hline PSV ratio & $\begin{array}{l}0.76 \\
(0.70-0.82)\end{array}$ & $\begin{array}{l}\geq 5.0^{\mathrm{a}} \\
\geq 5.3^{\mathrm{b}}\end{array}$ & $\begin{array}{l}77(66-87 ; 50 / 65) \\
71(59-82 ; 46 / 65)\end{array}$ & $\begin{array}{l}68(63-74 ; 179 / 262) \\
70(65-76 ; 184 / 262)\end{array}$ & $\begin{array}{l}38(29-46 ; 50 / 133) \\
37(29-46 ; 46 / 124)\end{array}$ & $\begin{array}{l}92(88-96 ; 179 / 194) \\
91(87-95 ; 184 / 203)\end{array}$ \\
\hline EDV ratio & $\begin{array}{l}0.79 \\
(0.72-0.84)\end{array}$ & $\begin{array}{l}\geq 6.2^{\mathrm{a}} \\
\geq 9.0^{\mathrm{b}}\end{array}$ & $\begin{array}{l}86(78-95 ; 56 / 65) \\
72(61-83 ; 47 / 65)\end{array}$ & $\begin{array}{l}62(56-68 ; 162 / 261) \\
72(67-78 ; 188 / 261)\end{array}$ & $\begin{array}{l}36(29-44 ; 56 / 155) \\
39(30-48 ; 47 / 120)\end{array}$ & $\begin{array}{l}95(91-98 ; 162 / 171) \\
91(87-95 ; 188 / 206)\end{array}$ \\
\hline \multicolumn{7}{|c|}{3 best combination of parameters (out of 28 ) } \\
\hline Parameters & \multicolumn{2}{|c|}{ Thresholds } & Sensitivity & Specificity & PPV & NPV \\
\hline Stenosis EDV and Stenosis PI & \multicolumn{2}{|c|}{$\begin{array}{l}\geq 114 \text { and/or } \geq 1.70^{\mathrm{a}} \\
\geq 118 \text { and/or } \geq 2.15^{\mathrm{b}}\end{array}$} & $\begin{array}{l}89(82-97 ; 58 / 65) \\
75(65-86 ; 49 / 65)\end{array}$ & $\begin{array}{l}63(57-69 ; 171 / 271) \\
75(70-80 ; 203 / 271)\end{array}$ & $\begin{array}{l}37(93-99 ; 58 / 158) \\
42(33-51 ; 49 / 117)\end{array}$ & $\begin{array}{l}96(93-99 ; 171 / 178) \\
93(89-96 ; 203 / 219)\end{array}$ \\
\hline CCA EDV and EDV Ratio & \multicolumn{2}{|l|}{$\begin{array}{l}\leq 7 \text { and } / \text { or } \geq 7.8^{\mathrm{a}} \\
\leq 7 \text { and } / \text { or } \geq 9.8^{\mathrm{b}}\end{array}$} & $\begin{array}{l}83(74-92 ; 54 / 65) \\
75(65-86 ; 49 / 65)\end{array}$ & $\begin{array}{l}69(63-74 ; 179 / 261) \\
75(70-80 ; 196 / 261)\end{array}$ & $\begin{array}{l}40(31-48 ; 54 / 136) \\
43(34-52 ; 49 / 114)\end{array}$ & $\begin{array}{l}94(91-98 ; 179 / 190) \\
92(89-96 ; 196 / 212)\end{array}$ \\
\hline Stenosis EDV and CCA EDV & \multicolumn{2}{|c|}{$\begin{array}{l}\geq 114 \text { and } / \text { or } \leq 7^{\mathrm{a}} \\
\geq 110 \text { and } / \text { or } \leq 4^{\mathrm{b}}\end{array}$} & $\begin{array}{l}83(74-92 ; 54 / 65) \\
74(63-85 ; 48 / 65)\end{array}$ & $\begin{array}{l}70(64-75 ; 182 / 261) \\
74(69-79 ; 193 / 261)\end{array}$ & $\begin{array}{l}41(32-49 ; 54 / 133) \\
41(32-50 ; 48 / 116)\end{array}$ & $\begin{array}{l}94(91-98 ; 182 / 193) \\
92(88-96 ; 193 / 210)\end{array}$ \\
\hline
\end{tabular}

Data are \% (95\%CI; n/N). AUC area under the curve, $N P V$ negative predictive value, $P P V$ positive predictive value. Stenosis PSV, Stenosis EDV, CCA $\mathrm{PSV}$, and CCA EDV are in $\mathrm{cm} / \mathrm{s}$

${ }^{a}$ Thresholds set at maximum Youden index

${ }^{\mathrm{b}}$ Thresholds set at maximum $\mathrm{H}$-index

future because recent studies reveal that some near-occlusions might benefit from revascularization [22-29].

Strengths of the study are relatively large size, dedicated near-occlusion data collection, and use of same interpretation approach and image interpreter for the angiographic comparison as the pooled analysis of the NASCET and ECST trials [1]. A limitation was that not all cases were examined with both ultrasound and CTA. Eleven cases had missing flow velocity data, mainly in the CCA, but all were in the control group of conventional stenosis. Although CTA, and not conventional digital subtraction angiography, was used as angiographic comparison, near-occlusions are well diagnosed on CTA $[2,3]$. Our approach to combine different parameters should be interpreted with caution as it might have caused model-overfitting. That is, the results are, if anything, likely an overestimation of diagnostic performance. Therefore, the lack of clear diagnostic improvement with two common parameters compared to one common parameter or alternative threshold approaches makes it unlikely that any combination of these common parameters works well. Efforts to improve near-occlusion diagnostics should rather focus on assessing new parameters such as distal velocity and contrast use.

Conclusions Near-occlusion is difficult to diagnose with commonly used carotid ultrasound methods, foremost lacking in sensitivity. Improved carotid ultrasound methods are needed if ultrasound is to retain its position as sole preoperative modality.

Acknowledgements Open access funding provided by Umea University. The authors want to thank the personnel at the various radiology departments in Northern Sweden that performed the CTA examinations and the personnel at the Department of Clinical Physiology at the University Hospital of Northern Sweden that performed the ultrasound examinations.

Author contribution Elias Johansson: idea, design, funding, data gathering, analysis, manuscript writing, and edit 
Davide Vanoli: data gathering, manuscript edit

Isa Bråten-Johansson: data gathering, manuscript edit

Lucy Law: data gathering, manuscript edit

Richard I Aviv: data gathering, manuscript edit

Allan J Fox: co-design, data gathering, manuscript edit

Funding All funding was received by EJ via his institution. This study was funded by the Knut and Alice Wallenberg Foundation, Region Västerbotten, the research fund for neurological research at the University Hospital of Northern Sweden, the Swedish Stroke fund, the Northern Swedish Stroke fund, and the Swedish Medical Association.

\section{Declarations}

Conflict of interest The authors declare no conflict of interest.

Ethical approval The study was approved by the regional ethics review board in Umeå, Sweden. All procedures performed in the studies involving human participants were in accordance with the ethical standards of the regional board and with the 1964 Helsinki Declaration and its later amendments.

Informed consent Need for consent was waived by the review board due to the observational nature of the study.

Open Access This article is licensed under a Creative Commons Attribution 4.0 International License, which permits use, sharing, adaptation, distribution and reproduction in any medium or format, as long as you give appropriate credit to the original author(s) and the source, provide a link to the Creative Commons licence, and indicate if changes were made. The images or other third party material in this article are included in the article's Creative Commons licence, unless indicated otherwise in a credit line to the material. If material is not included in the article's Creative Commons licence and your intended use is not permitted by statutory regulation or exceeds the permitted use, you will need to obtain permission directly from the copyright holder. To view a copy of this licence, visit http://creativecommons.org/licenses/by/4.0/.

\section{References}

1. Fox AJ, Eliasziw M, Rothwell PM et al (2005) Identification, prognosis, and management of patients with carotid artery near occlusion. Am J Neuroradiol 26:2086-2094

2. Johansson E, Fox AJ (2016) Carotid near-occlusion: a comprehensive review, part 1-definition, terminology, and diagnosis. Am J Neuroradiol 37:2-10

3. Johansson E, Fox AJ (2016) Carotid near-occlusion: a comprehensive review, part 2 - prognosis and treatment, pathophysiology, confusions, and areas for improvement. Am J Neuroradiol 37: 200-204

4. Brott TG, Halperin JL, Abbara S, Bacharach JM, Barr JD, Bush RL, Cates CU, Creager MA, Fowler SB, Friday G, Hertzberg VS, McIff E, Moore WS, Panagos PD, Riles TS, Rosenwasser RH, Taylor AJ, American College of Cardiology, American Stroke Association, American Association of Neurological Surgeons, American College of Radiology, American American College of Radiology, Society of NeuroInterventional Surgery, Society for Vascular Medicine, Society for Vascular Surgery (2011) 2011 ASA/ACCF/AHA/AANN/AANS/ACR/ ASNR/CNS/SAIP/SCAI/ SIR/SNIS/SVM/SVS guideline on the management of patients with extracranial carotid and vertebral artery disease. Circulation 124: e54-e130

5. Naylor AR, Ricco JB, de Borst GJ, Debus S, de Haro J, Halliday A, Hamilton G, Kakisis J, Kakkos S, Lepidi S, Markus HS, McCabe DJ, Roy J, Sillesen H, van den Berg JC, Vermassen F, ESVS Guidelines Committee, Kolh P, Chakfe N, Hinchliffe RJ, Koncar I, Lindholt JS, Vega de Ceniga M, Verzini F, ESVS Guideline Reviewers, Archie J, Bellmunt S, Chaudhuri A, Koelemay M, Lindahl AK, Padberg F, Venermo M (2018) Management of atherosclerotic carotid and vertebral artery disease: 2017 clinical practice guidelines of the European Society for Vascular Surgery (ESVS). Eur J Vasc Endovasc Surg 55:3-81

6. von Reutern GM, Goertler MW, Bornstein NM, del Sette M, Evans DH, Hetzel A, Kaps M, Perren F, Razumovky A, von Reutern M, Shiogai T, Titianova E, Traubner P, Venketasubramanian N, Wong LK, Yasaka M, Neurosonology Research Group of the World Federation of Neurology (2012) Grading carotid stenosis using ultrasonic methods. Stroke 43:916-921

7. Grant EG, Benson CB, Moneta GL, Alexandrov AV, Baker JD, Bluth EI, Carroll BA, Eliasziw M, Gocke J, Hertzberg BS, Katanick S, Needleman L, Pellerito J, Polak JF, Rholl KS, Wooster DL, Zierler RE (2003) Carotid artery stenosis: gray-scale and Doppler US diagnosis-Society of Radiologists in Ultrasound Consensus Conference. Radiology 229:340-346

8. El-Saden SM, Grant EG, Hathout GM et al (2001) Imaging of the internal carotid artery: the dilemma of total versus near total occlusion. Radiology 221:301-308

9. Mansour MA, Mattos MA, Hood DB et al (1995) Detection of total occlusion, string sign, and preocclusive stenosis of the internal carotid artery by color-flow duplex scanning. Am J Surg 170:154158

10. Hetzel A, Eckenweber B, Trummer B, Wernz M, Schumacher M, von Reutern GM (1998) Colour-coded duplex sonography of preocclusive carotid stenoses. Eur J Ultrasound 8:183-191

11. Khangure SR, Benhabib H, Machnowska M, Fox AJ, Grönlund C, Herod W, Maggisano R, Sjöberg A, Wester P, Hojjat SP, Hopyan J, Aviv RI, Johansson E (2018) Carotid near-occlusion frequently has high peak systolic velocity on Doppler ultrasound. Neuroradiology 60:17-25

12. Bartlett ES, Walters TD, Symons SP, Fox AJ (2006) Diagnosing carotid stenosis near-occlusion by using CT angiography. Am J Neuroradiol 27:632-637

13. Johansson E, Aviv RI, Fox AJ (2020) Atherosclerotic ICA stenosis coincidental with ICA asymmetry associated with circle of Willis variations can mimic near-occlusion. Neuroradiology 62:101-104

14. Fox AJ (1993) How to measure carotid stenosis. Radiology 186: 316-318

15. Oates CP, Naylor AR, Hartshorne T, Charles SM, Fail T, Humphries K, Aslam M, Khodabakhsh P (2009) Joint recommendations for reporting carotid ultrasound investigations in the United Kingdom. Eur J Vasc Endovasc Surg 37:251-261

16. Hansen F, Bergqvist D, Lindblad B, Lindh M, Mätzsch T, Länne T (1996) Accuracy of duplex sonography before carotid endarterectomy - a comparison with angiography. Eur J Vasc Endovasc Surg 12:331-336

17. Palacios-Mendoza MA, García Pastor A, Gil-Núñez A et al (2020) Ultrasonographic and hemodynamic characteristics of patients with symptomatic carotid near-occlusion: results from a multicenter registry study. Neuroradiology E-pub. https://doi.org/10.1007/s00234020-02567-w

18. Johansson E, Benhabib H, Herod W, Hopyan J, Machnowska M, Maggisano R, Aviv R, Fox AJ (2019) Carotid near-occlusion can be identified with ultrasound by low flow velocity distal to the stenosis. Acta Radiol 60:396-404

19. Ventura CA, da Silva ES, Cerri GG (2015) Can contrast-enhanced ultrasound with second-generation contrast agents replace 
computed tomography angiography for distinguishing between occlusion and pseudo-occlusion of the internal carotid artery? Clinics $70: 1-6$

20. Wardlaw JM, Chappell FM, Stevenson M et al (2006) Accurate, practical and cost-effective assessment of carotid stenosis in the UK. Health Technol Assess 10:30

21. Wardlaw JM, Chappell FM, Best JJK, Wartolowska K, Berry E (2006) Non-invasive imaging compared with intra-arterial angiography in the diagnosis of symptomatic carotid stenosis: a metaanalysis. Lancet 367:1503-1512

22. García-Pastor A, Gil-Núñez A, Ramírez-Moreno JM, GonzálezNafría N, Tejada J, Moniche F, Portilla-Cuenca JC, MartínezSánchez P, Fuentes B, Gamero-García MÁ, Alonso de Leciñana M, Cánovas-Verge D, Aladro Y, Parkhutik V, Lago-Martín A, de Arce-Borda AM, Usero-Ruíz M, Delgado-Mederos R, Pampliega A, Ximenez-Carrillo Á, Bártulos-Iglesias M, Castro-Reyes E, Stroke Project of the Spanish Cerebrovascular Diseases Study Group (2017) Early risk of recurrent stroke in patients with symptomatic carotid near-occlusion: Results from CAOS, a multicenter registry study. Int J Stroke 12:713-719

23. García-Pastor A, Gil-Núñez A, Ramírez-Moreno JM, GonzálezNafría N, Tejada J, Moniche F, Portilla-Cuenca JC, MartínezSánchez P, Fuentes B, Gamero-García MÁ, Alonso de Leciñana M, Masjuán J, Cánovas-Verge D, Aladro Y, Parkhutik V, LagoMartín A, de Arce-Borda AM, Usero-Ruíz M, Delgado-Mederos R, Pampliega A, Ximenez-Carrillo Á, Bártulos-Iglesias M, CastroReyes E, the Stroke Project of the Spanish Cerebrovascular Diseases Study Group (2019) The risk of recurrent stroke at 24 months in patients with symptomatic carotid near-occlusion: results from CAOS, a multicentre registry study. Eur J Neurol 26:13911398

24. Gu T, Aviv RI, Fox AJ, Johansson E (2020) Symptomatic carotid near-occlusion causes a high risk of recurrent ipsilateral ischemic stroke. J Neurol 267:522-530

25. Johansson E, Öhman K, Wester P (2015) Symptomatic carotid near-occlusion with full collapse might cause a very high risk of stroke. J Intern Med 277:615-623

26. Kim J, Male S, Damania D, Jahromi BS, Tummala RP (2019) Comparison of carotid endarterectomy and stenting for symptomatic internal carotid artery near-occlusion. AJNR Am J Neuroradiol 40:1207-1212

27. Meershoek AJA, Vonken EPA, Nederkoorn PJ et al (2019) Carotid endarterectomy in patients with recurrent symptoms associated with an ipsilateral carotid artery near-occlusion with full collapse. J Neurol 265:1900-1905

28. Meershoek AJA, de Vries EE, den Ruijter HM et al (2019) Metaanalysis of the outcomes of treatment of internal carotid artery near occlusion. Br J Surg 106:665-671

29. Arat A, Cay F, Cil BE et al (2020) Relevance of distal arterial collapse in stenting of atherosclerotic near-occlusion of the carotid artery. AJNR 41:1054-1060

Publisher's note Springer Nature remains neutral with regard to jurisdictional claims in published maps and institutional affiliations. 